\title{
Efficient Recycling and Reuse of Waste Concrete on a Construction Site
}

\author{
Daguang Han, Yupeng Yang, Chunli Ying, Zeger Sierens, Hongbo Fan, and Jiabin Li
}

Synopsis: During the construction of the high-speed rail from Wuzhong to Yinchuan in China, a huge amount of concrete wastes was generated. From the viewpoint of reducing the transportation cost, decreasing the consumption of natural resources and saving land space, it was decided to recycle and reuse of the concrete wastes in the construction work of the high-speed rail. This paper deals with the technical feasibility of reusing the concrete wastes taking into account the actual conditions on the construction site. The concrete wastes were crushed in a plant for producing natural coarse aggregates into recycled concrete aggregates (RCAs). Laboratory tests on the properties of the RCAs were carried out. It was found that that the physical and mechanical properties of the RCAs can meet the requirements in various standards. Then, experiments on the utilization of RCAs to manufacture concrete blocks for highway bank protection revetment were performed. The preliminary experimental results are found to be very encouraging.

Keywords: concrete wastes, recycling and reuse, recycled concrete aggregates (RCAs), concrete blocks 
Han et al.

Daguang Han is a senior engineer (associate professor) and director of the BIM Engineering Centre in the Faculty of Civil Engineering, Chongqing Jiaotong University, China. He received his $\mathrm{PhD}$ degree in Structural Engineering in 2012 from University of the German Federal Armed Forces, Germany. His research interests include Building Information Modeling (BIM) as well as smart infrastructure and construction.

Yupeng Yang is a chief engineer at the fifth Engineering Co., Ltd., China Railway 16th Bureau Group, Hebei, China. He received his bachelor degree in Civil Engineering in 2005 from Shenyang Jianzhu University, China.

Chunli Ying is a research fellow in the Faculty of Civil Engineering, Chongqing Jiaotong University, China and a pre-doctor program student at KU Leuven, Belgium. Her research interest is the use of BIM technique in selective demolition of buildings and infrastructure.

Zeger Sierens is a second-year PhD student in the Department of Civil Engineering, KU Leuven, Belgium. He received his bachelor and master degree from KU Leuven. His PhD research work is focused on the use of recycled concrete aggregates (RCAs) in precast non-prestressed and prestressed concrete elements.

Hongbo Fan is a postgraduate student in the Faculty of Civil Engineering, Chongqing Jiaotong University, China. His research interest is recycling and reuse of demolished concrete.

Jiabin $\mathbf{L i}$ is a professor in the Department of Civil Engineering and holder of the Chair in Smart \& Sustainable Infrastructure and Zero-Waste in Construction, KU Leuven, Belgium. He received his $\mathrm{PhD}$ degree in Structural Engineering in 2011 from University of Leipzig, Germany. His main research interests include recycling and reuse in construction, smart and sustainable infrastructure, analysis and design of structural concrete, as well as numerical modeling of concrete materials and structures.

\section{INTRODUCTION}

A large number of high speed rail projects are currently ongoing in China. The rail between Wuzhong and Yinchuan, which has a length of $39.6 \mathrm{~km}$, belongs to a part of the Yinchuan-Xi'an high speed rail. The total budget is about 212 million Euros and this project is planned to be completed to the end of 2018. During the construction work, a huge amount of concrete waste has been produced. More and more waste concrete will be further generated. These concrete wastes are mainly resulted from the following sources:

- The cut (removal) of the heads of plain concrete drilled piles. In this project, a lot of plain concrete piles are used as deep foundations. The strength class of the pile concrete is mainly C16/20.

- The demolition of many concrete and reinforced concrete structures and infrastructures. Fig. 1(a) presents a reinforced concrete bridge near the Yinchuan International Airport, which will be demolished soon. This bridge is still at a relatively young age (less than 1 year) and the strength class of the bridge concrete is C40/50.

- Laboratory - cast concrete specimens. Owing to the high requirements on the quality of the rail concrete, numerous specimens were cast in the laboratory to ensure the quality of the concrete. Fig. 1(b) shows some concrete cubes and prisms after mechanical or durability tests. In addition, there are also some rejected structural precast elements, which accounts for a relatively small part of the concrete wastes.

It is well known that idea of recycling of old concrete as recycled concrete aggregates (RCAs) and then reuse of the RCAs to manufacture of concrete is not new. The research work on this topic can be traced to just after the World War II [1]. In the past several decades, numerous studies have been carried out in Belgium, Germany, the Nederland, Japan, the UK and later Canada, USA, China, Italy, Spain, France and other countries. Many studies on the crushing and processing technology of old concrete, the mixing proportion of concrete with RCAs, often called recycled aggregate concrete (RAC), the mechanical properties and durability of RAC as well as the behaviour and design of structural elements with RAC $[2,3]$. These intensive research efforts have successfully demonstrated that the utilisation of RCAs and RAC is technical feasible, even in structural applications. In many cases, an economical benefit can also be achieved. This has opened many potential markets for RCAs and RAC. Despite the technology is becoming more and more mature, the implementation of the idea of recycling and reuse of concrete wastes in this project still meets some big challenges. These challenges include:

- No special designed recycling plants for crushing construction and demolition wastes are available in the area where the construction work locates;

- It is not easy to install mobile crushers on the construction site due to the possible noise and dust during the processing of the concrete wastes;

- Adequate knowledge such as the processing and the quality of RCAs, the mix design procedure of RAC and the effect of RCAs on the concrete properties, are missing; 
- The construction schedule is very tight, which means that the recycling and reuse of concrete wastes should not disturb the work plan and not add too much additional work, for instance, to the laboratory technicians and construction workers.

To overcome these challenges, it was decided to carry out the work under the consulting of an experienced academic institution for recycling and reuse of concrete materials. The research group RecyCon - Recycling in Construction at KU Leuven (Belgium) was then commissioned to this end. Based on the advices of the consultants, the following procedures were taken:

- Processing the concrete wastes in a crushing plant for natural coarse aggregates;

- Only using coarse RCAs in manufacturing new concrete to make sure that the quality of the concrete can meet the code requirements;

- Testing the produced RCAs by using of the Chinese Standard for natural aggregates and imposing the requirements for RCAs in the European Standard EN 12620: 2013 + A1: 2016 Aggregates for Concrete and the Belgian Standard NBN B 15-001: 2017 Concrete: Specification, Performance, Production and Conformity;

- Firstly utilising of RCAs in secondary or non-load bearing elements and then considering for structural use.

\section{PROCESSING AND PROPERTIES OF RECYCLED CONCRETE AGGREGATES}

\section{Processing of concrete wastes}

A plant for crushing natural stones (rocks) as coarse aggregates for concrete was used to crush the concrete. This is the closest plant to the collection site of the concrete wastes, with a distance of around $80 \mathrm{~km}$. Fig. 2 shows the crushing plant.

Since the crushing procedure has a very important influence on the properties of RCAs, the quality of the processing of the crushing plant must be checked. For this aim, the laboratory - cast concrete specimens were crushed in this crushing plant and the properties of the produced RCAs were examined. The parent concrete has a maximum aggregate size of $31.5 \mathrm{~mm}$ with a strength class of C30/37 to C35/45. The concrete specimens were firstly subjected to a jaw crusher and then a hammer crusher for further shaping the RCAs. Finally, the RCAs were sieved according to three sizes: $5-10 \mathrm{~mm}, 10-20 \mathrm{~mm}$ and $16-31.5 \mathrm{~mm}$. The whole procedure does not differ from that for producing coarse natural aggregates. The produced RCAs of different sizes are illustrated in Fig. 3. It can be seen from the figure that the RCAs have an angular and rough surface, irrespective of the sizes. The RCAs are in general original natural aggregates with old mortar attached on them. This is quite consistent with many previous findings, such as $[1,4,5,6]$.

\section{Properties of produced RCAs}

The laboratory tests on the properties of the RCAs were carried out according to the Chinese Standard $G B / T$ 14685 -2011 Pebble and Crushed Stone for Construction. The tested items included: the grading, particle density, bulk density, void ratio, flakiness index, and the water absorption as well as the crushing value.

The grading curves of the RCAs are presented in Fig. 4. In Fig. 4(a) to (c), the curves are for the aggregates directly obtained from the crushing plant. It can be seen that the grading curves for all the three sizes of aggregates fall within the maximum and minimum limits given in the Chinese Standard GB/T $14685-2011$. This means the RCAs can meet the grading requirement for aggregates used in concrete. Fig. 4(d) shows the grading curve of a recomposed aggregate, in which the proportion of the aggregates of $5-10 \mathrm{~mm}, 10-20 \mathrm{~mm}$ and 16 $31.5 \mathrm{~mm}$ is $20 \%, 50 \%$ and $30 \%$, respectively. It can be seen that the grading curve of the recomposed aggregate also falls within the envelope for coarse aggregate for using in concrete.

The test data for the other physical and mechanical properties of the RCAs are presented in Tab.1. From this table, it can be seen that the RCAs obtained in this work are able to meet the requirements for RCAs in the standards EN 206:2013 +A1: 2016 and NBN B 15-001: 2017 as well as the Chinese Standard GB/T 25177 2010 Recycle Coarse Aggregate for Concrete.

\section{USE OF RECYCLED CONCRETE AGGREGATES TO PRODUCE CONCRETE BLOCKS}

As described above, the produced RCAs from the concrete wastes on this construction site and using the crushing plant for natural coarse aggregates have high quality and can meet the code requirements. Therefore, it is possible to use the RCAs for manufacturing concrete. Based on actual conditions and taking into account the relatively insufficient knowledge and experiences of the construction team, it was decided to firstly utilise the RCAs in manufacturing precast concrete blocks, shown in Fig. 5, for highway bank protection revetments. Since the wall thickness of the concrete block is small, which is only $5 \mathrm{~cm}$, only the RCAs of $5-10 \mathrm{~mm}$ was used to produce the concrete blocks.

According to the exposed environment conditions of the concrete blocks and the durability requirements of the Chinese Code TB 10005-2010 + J1167-2011: Durability Design on Concrete Structures of Railway, a minimum concrete strength class $\mathrm{C} 25$ (characteristic cube compressive strength is $25 \mathrm{MPa}$ ), which corresponds to a 
Han et al.

C20/25 in the Eurocode 2 [8], is required. In addition, considering the production conditions of the concrete blocks, a slump of $180-200 \mathrm{~mm}$ for the concrete mixture is needed to facilitate the manufacture of the blocks.

\section{Materials}

A normal hardening Portland cement with low alkali content (CEM I $42.5 \mathrm{~N} \mathrm{LA}$ ), supplied by a local cement manufacturer, was used for the concrete mixtures. The utilized sand was natural river sand, which was also used in other concrete mixtures in this construction work. The fraction size of the sand was $0-5 \mathrm{~mm}$. The used coarse aggregates were the produced RCAs with a fraction of $5-10 \mathrm{~mm}$, as already mentioned above. No natural coarse aggregates were used in the test. Normal tap water was used and a high efficient superplasticizer was also employed to achieve the required workability of the concrete mixture.

\section{Concrete mixtures}

Based on several trial tests, three concrete mixtures were used in the production of the concrete for the blocks. The proportioning of the mixtures is shown in Table 2. The three mixtures have the same water/cement ratio but the amount of the cement paste is different. This aims to investigate the effect of the cement paste amount on the workability of the concrete mixture and on the freezing - thawing resistance of the concrete. It should be noted that the unit weight of the materials shown in Table 2 is only valid for absolutely dry materials. In the actual mixing of the concrete, the moisture content of the sand was taken into account and compensation water due to the high water absorption of the RCAs was also added. The quantity of the compensation water was determined according to the amount of the RCAs and their water absorption.

\section{Specimen preparation}

The concrete mixtures were prepared in the central laboratory of the construction site by using of a mixer. The slump of all the three concrete mixtures were found to be in the range of $180-200 \mathrm{~mm}$, indicating that the requirement for the workability of the concrete mixtures was satisfied.

After the slump test, the concrete mixtures were cast into $150 \times 150 \times 150 \mathrm{~mm}$ steel molds. For each mixture, a total of 21 specimens were produced to measure the compressive strength of concrete at $1 \mathrm{~d}, 2 \mathrm{~d}, 3 \mathrm{~d}, 7 \mathrm{~d}, 14 \mathrm{~d}, 21$ $\mathrm{d}$ and $21 \mathrm{~d}$. After $24 \mathrm{~h}$, the concrete specimens were demolded and three specimens were tested immediately and the rest of the specimens were cured in a climate room with a temperature of $20^{\circ} \mathrm{C}$ and relative humidity $95 \%$ prior to the test.

\section{Concrete strength test results and analysis}

The compressive strength tests on the concrete specimens were carried out according to the Chinese Standard GB50081-2002: Test method of mechanical properties on ordinary concrete. For each concrete mixture at each curing age, three specimens were tested. The test results are presented in Table 3, in which data represents the average results of three specimens. It can be seen that for all mixtures, the compressive strength of the concrete increases with the curing age, however, the main strength increase happens in the first 7 days; after that the increase of the compressive strength of the concrete becomes much slower. This is in fact consistent with that for conventional concrete with natural aggregates. At a curing age of $28 \mathrm{~d}$, all the three concrete mixtures show similar results and all mixtures reached the strength requirement for the concrete blocks.

Zhu [7] proposed the following equation to describe the compressive strength of concrete with time:

$$
f_{c u}(t)=f_{c u, 28}\left[1+\lambda \ln \left(\frac{t}{28}\right)\right]
$$

in which, $\lambda$ is a parameter depending on the used cement type. For normal Portland cement, $\lambda=0.1727$.

In the current Eurocode 2 [8], Eq. (2) is used to describe the time-dependent compressive strength of concrete.

$$
f_{c u}(t)=f_{c u, 28} \exp \left\{s\left[1-\left(\frac{28}{t}\right)^{\frac{1}{2}}\right]\right\}
$$

where, $s$ is also a coefficient that depends on the used cement type. For normal hardening cement. $s=0.25$.

In fact, Eq. (1) and (2) yield quite similar results. A comparison of the predictions of Eq. (2) with the test data is shown in Fig. 6. It can be seen that the predictions are in good agreement with the test data, which means this model is also suitable for concrete with the RCAs produced in this study. 


\section{Production of precast concrete blocks with RCAs}

After the successful development of the concrete mixtures, precast concrete blocks were produced with the RCAs. The concrete blocks were manufactured with plastic moulds, as shown in Fig. 7(a). Fig. 7(b) shows the casting of the concrete blocks while the blocks after demolding are shown in Fig. 7(c). No visible cracking due to the shrinkage of concrete was observed on the surface of the blocks, indicating satisfied surface quality.

\section{CONCLUSIONS AND REMARKS}

This paper provides a study on the recycling and reuse of concrete wastes on a construction site, which were generated due to the construction of a high-speed rail. The concrete wastes were crushed into recycled concrete aggregates (RCAs). Instead of being used in sub-bases for road works and similar low grade applications, the RCAs were used to manufacture concrete blocks for highway bank protection revetment, representing a valueadded application of the RCAs. In spite of several big challenges, the first efforts for producing concrete blocks with the RCAs in the laboratory were successful. The following conclusions can be drawn from this work:

- It is possible to obtain recycled concrete aggregates with good grading by making use of the crushing plant for natural coarse aggregates, where the concrete wastes are firstly crushed by a jaw crusher and then further shaped by a hammer crusher;

- The physical and mechanical properties of the RCAs can meet the requirements of different standards, demonstrating the viability of using this material for producing concrete. Since the parent concrete is generally young (less than 1 year) and contains nearly no contamination, the effect of the RCAs on the durability of concrete should not be a big concern;

- Through proper mixing, the concrete with RCAs can meet the requirements for both the workability and the compressive strength;

- The compressive strength of the concrete with the RCAs increases with the curing age. After 7 days, the strength increase becomes less significant, which is similar to that of conventional concrete with natural aggregates;

- The model for describing the compressive strength development of concrete in EN 1992-1-1 is also suitable for the concrete with the RCAs in this paper;

- Currently, large-scale productions of precast concrete blocks with the RCAs are being carried out. No big problems were detected during the manufacture.

\section{ACKNOWLEDGMENTS}

This work has been supported by a start-up funding (No. STG/16/011) granted to Jiabin Li from KU Leuven University of Leuven, Belgium. This financial support is gratefully acknowledged. During the research work presented in this paper, Professor Luc Boehme of KU Leuven provided many useful information and advices. The author would like to express their sincere acknowledgement for his invaluable help.

\section{NOTATION}

cube compressive strength at any time $t(\mathrm{MPa})$

cube compressive strength of concrete at 28 days (MPa)

a coefficient depending on the used type of cement

age of the concrete (days)

a coefficient depending on the used type of cement.

\section{REFERENCES}

[1] Hansen, T. C., "Recycled aggregates and recycled aggregate concrete: second State-of-the-Art Report developments 1945-1985", Materials and Structures, V. 19, No. 3, May 1986, pp 201-246.

[2] De Brito, J. and Saikia, N., "Recycled aggregate in concrete", Springer-Verlag London, 2013, 448pp.

[3] Fernando Pacheco-Torgal, F., Tam, V., Labrincha, J., Ding, Y. and De Brito, J., "Handbook of recycled concrete and demolition waste", Woodhead Publishing ,2013, 672pp.

[4] Boehme, L., Van Gysel, A., Vrijders, J., Joseph, M., and Claes, J., "Valorisation of recycled concrete aggregates in concrete C20/25 \& C25/30", ACCO, Leuven, 2012, 199pp.

[5] Li, J., Xiao, J. and Huang, J., "Influence of recycled coarse aggregate replacement percentages on compressive strength of concrete", Chinese Journal of Building Materials, V. 9, No. 3, June 2006, pp. 297-301.

[6] Xiao, J., Li, J and Zhang, Ch., "Mechanical properties of recycled aggregate concrete under uniaxial loading", Cement and Concrete Research, V. 35, No. 6, June 2005, pp. 1187-1194.

[7] Zhu, B. "Temperature stress and temperature control of mass concrete", China Electric Power Press, Beijing, 1999.

[8] EN 1992-1-1: Eurocode 2: Design of concrete structures - Part 1-1: General rules and rules for buildings. Brussels, 2004. 
Han et al.

\section{TABLES AND FIGURES}

Table 1 Physical and mechanical properties of the RCAs

\begin{tabular}{|c|c|c|c|c|c|}
\hline \multirow{2}{*}{ Properties } & \multicolumn{2}{|c|}{ Requirement } & \multicolumn{3}{c|}{ Test results } \\
\cline { 2 - 5 } & $\begin{array}{c}\text { EN 206: 2013 } \\
\text { NBN B 15-001 }\end{array}$ & GB/T 25177 & $5-10 \mathrm{~mm}$ & $10-20 \mathrm{~mm}$ & $16-31.5 \mathrm{~mm}$ \\
\hline $\begin{array}{c}\text { Particle density } \\
\left(\mathrm{kg} / \mathrm{m}^{3}\right)\end{array}$ & $\geq 2200$ & $>2450$ (Type I) & 2630 & 2600 & 2600 \\
\hline $\begin{array}{c}\text { Bulk density } \\
\left(\mathrm{kg} / \mathrm{m}^{3}\right)\end{array}$ & - & - & 1510 & 1530 & 1550 \\
\hline Void ratio (\%) & - & $<47$ (Type I) & 43 & 41 & 40 \\
\hline Flakiness index (\%) & $\leq 20$ & $<10$ & - & 2.5 & 1.8 \\
\hline $\begin{array}{c}\text { Water absorption } \\
24 \mathrm{~h}(\%)\end{array}$ & $\leq 10$ & $<5$ (Type II) & 4.5 & 4.6 & 4.4 \\
\hline $\begin{array}{c}\text { Crushing value } \\
(\%)\end{array}$ & - & $<12$ (Type I) & - & 12 & - \\
\hline
\end{tabular}

Table 2 Concrete mixtures

\begin{tabular}{|c|c|c|c|c|c|}
\hline \multirow{2}{*}{ Mixture } & \multicolumn{5}{|c|}{ Unit weight $\left(\mathrm{kg} / \mathrm{m}^{3}\right)$} \\
\cline { 2 - 6 } & Cement & Sand & RCAs & Water & Superplasticizer \\
\hline Mix 1 & 310 & 1245 & 555 & 186 & 2.17 \\
\hline Mix 2 & 320 & 1220 & 555 & 192 & 1.60 \\
\hline Mix 3 & 350 & 1147 & 555 & 210 & 1.40 \\
\hline
\end{tabular}

Note: the weight of the RCAs refers to dry material.

Table 3 Test results of compressive strength

\begin{tabular}{|c|c|c|c|c|c|c|c|}
\hline \multirow{2}{*}{ Mixture } & \multicolumn{7}{|c|}{ Cube compressive strength (MPa) } \\
\cline { 2 - 8 } & $1 \mathrm{~d}$ & $2 \mathrm{~d}$ & $3 \mathrm{~d}$ & $7 \mathrm{~d}$ & $14 \mathrm{~d}$ & $21 \mathrm{~d}$ & $28 \mathrm{~d}$ \\
\hline Mix 1 & 10.39 & 15.82 & 17.99 & 23.07 & 27.40 & 29.65 & 29.98 \\
\hline Mix 2 & 10.51 & 16.04 & 18.80 & 23.23 & 27.42 & 29.63 & 31.42 \\
\hline Mix 3 & 8.28 & 12.73 & 19.46 & 24.37 & 28.33 & 27.77 & 31.53 \\
\hline
\end{tabular}

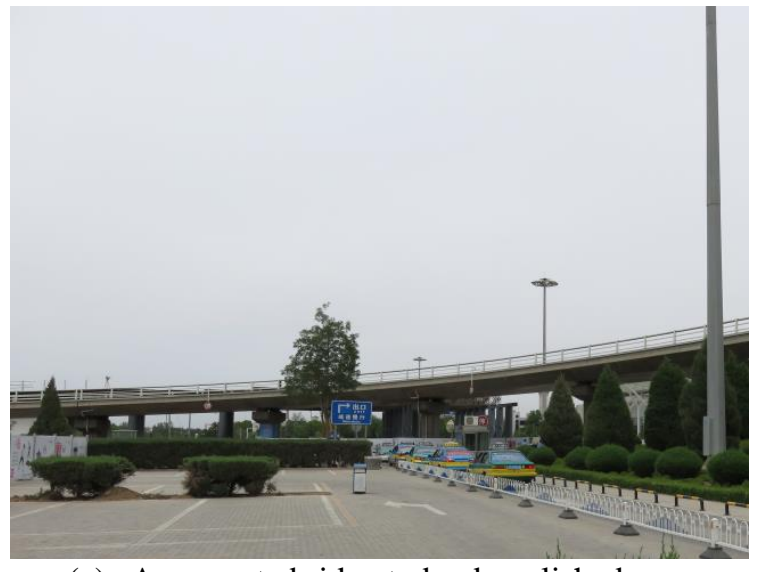

(a) A concrete bridge to be demolished

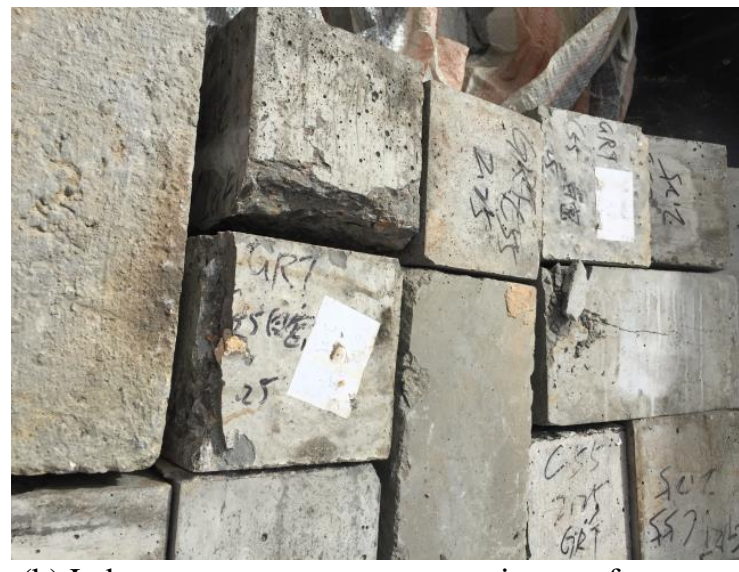

(b) Laboratory -cast concrete specimens after tests

Fig.1 Some sources for generating concrete wastes on the construction site 


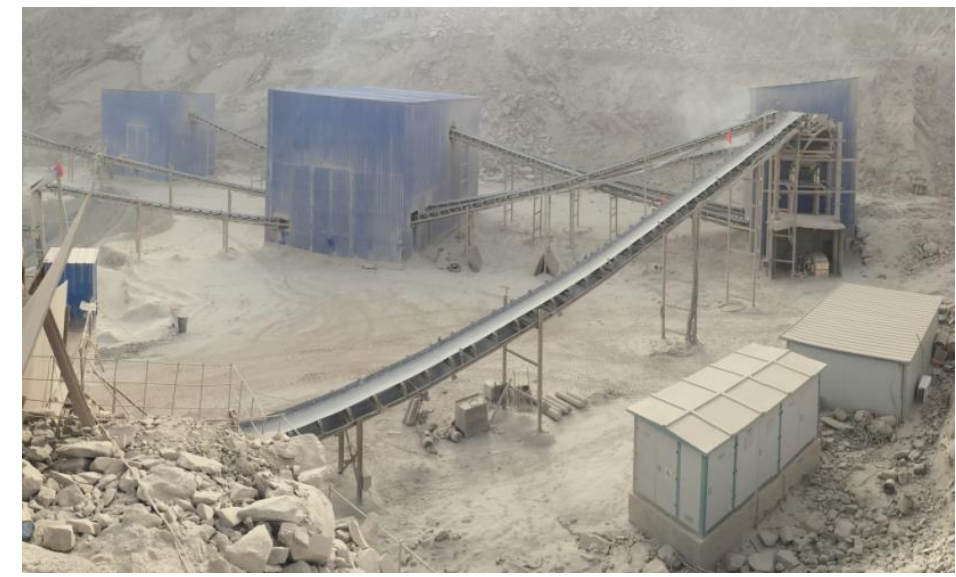

Fig. 2 Crushing plant for concrete aggregates

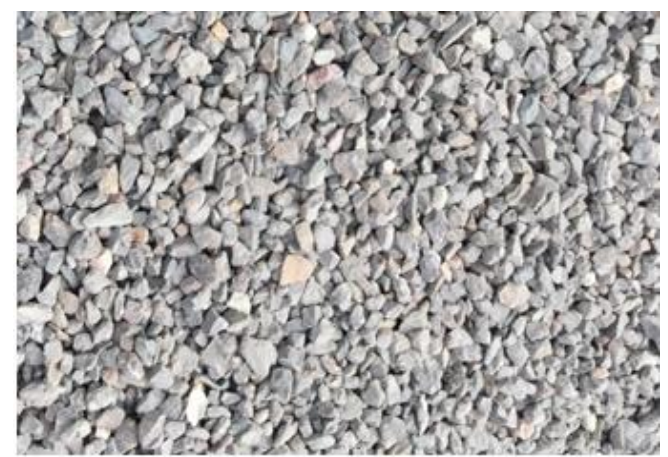

(a) $5-10 \mathrm{~mm}$

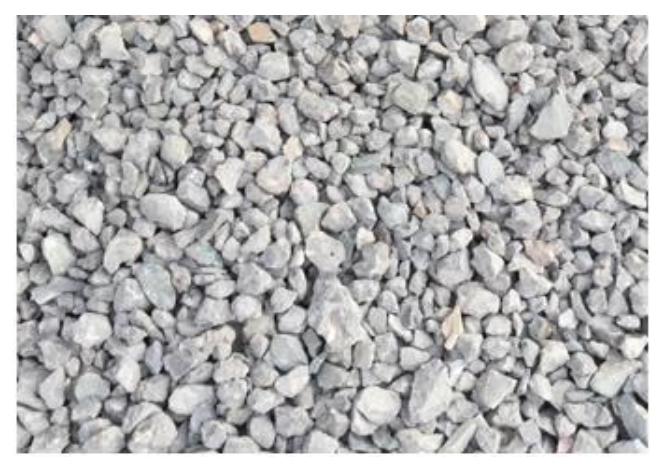

(b) $10-20 \mathrm{~mm}$

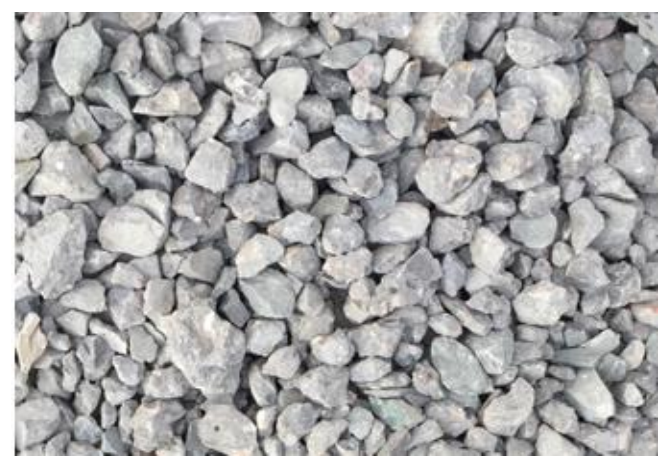

(c) $16-31.5 \mathrm{~mm}$

Fig. 3 Recycled concrete aggregates (of different sizes)

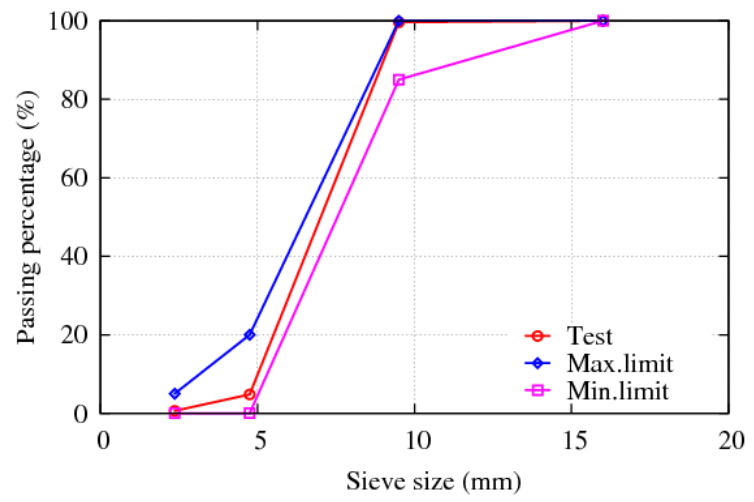

(a) $5-10 \mathrm{~mm}$

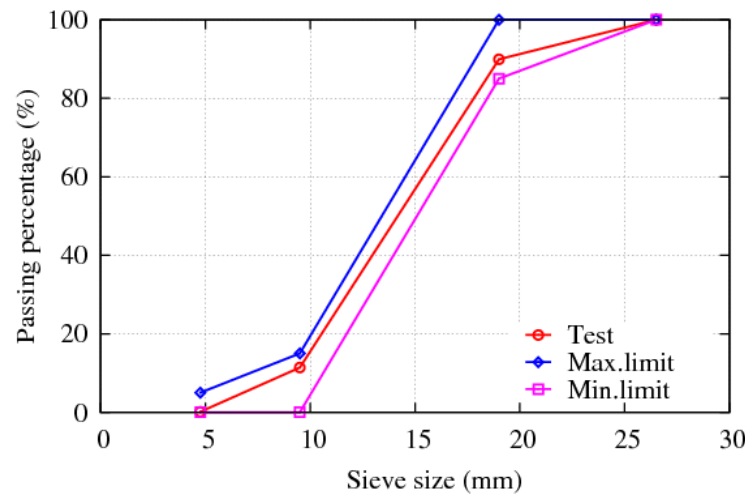

(b) $10-20 \mathrm{~mm}$ 
Han et al.

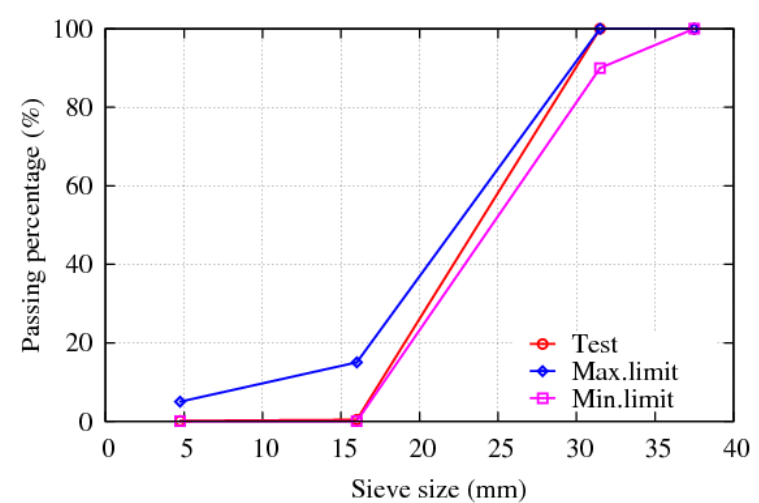

(c) $16-31.5 \mathrm{~mm}$

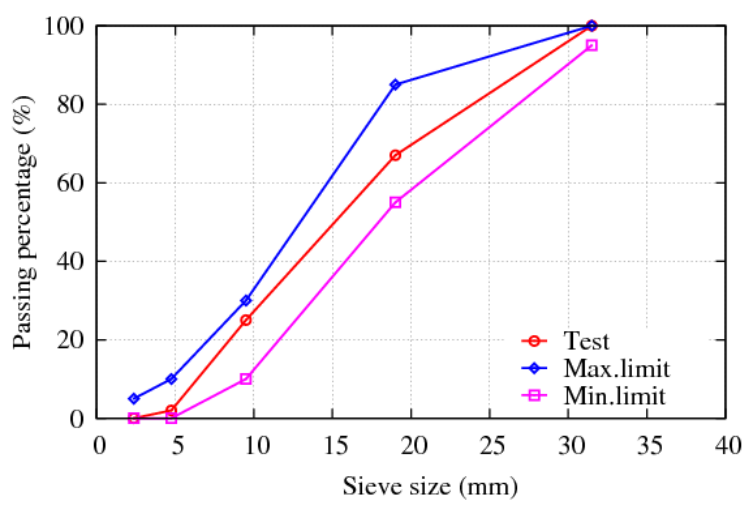

(d) $5-31.5 \mathrm{~mm}$

Fig. 4 Grading curves of the RCAs

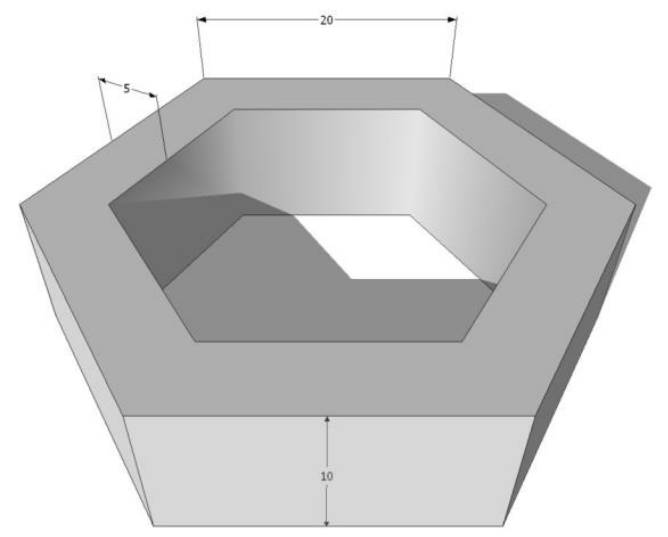

Fig. 5 Precast concrete blocks for highway bank protection revetment

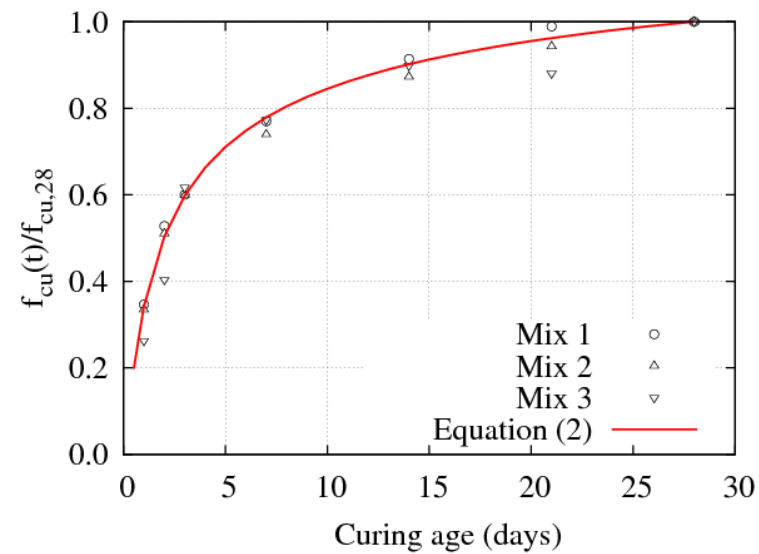

Fig. 6 The raito $f_{\mathrm{cu}}(t) / f_{\mathrm{cu}}, 28$ - ratio vers. curing age 
Efficient Recycling and Reuse of Waste Concrete on a Construction Site

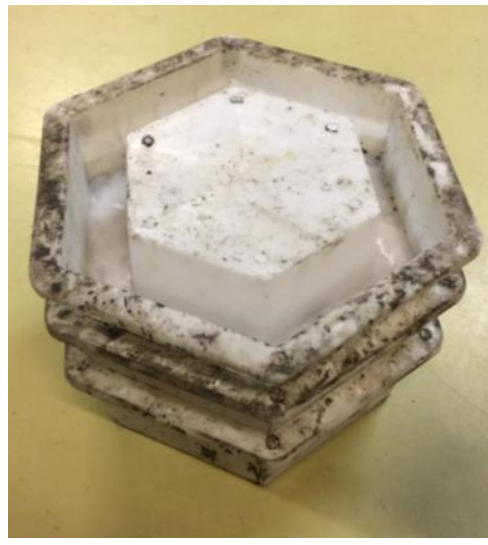

(a) Mold for concrete blocks

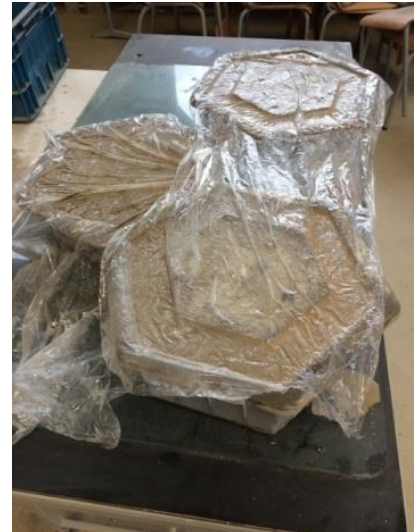

(b) Casting concrete blocks

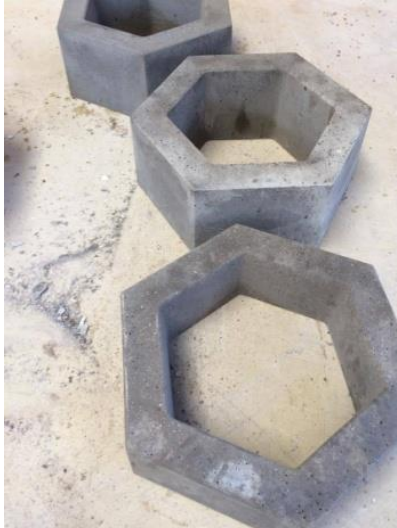

(c) Concrete blocks after demolding

Fig. 7 Concrete blocks with RCAs 
Han et al. 